\title{
Benign Endikasyonlu Olgularda Histerektomi Yöntemlerinin Karşılaştırılması
}

\section{Comparing of Hysterectomy Approaches For Cases with Bening Indication}

\author{
Dilek Sağlam, Mustafa Üner Karacaoğlu, Tolga Karacan, Hikmet Koçer, \\ Hüseyin Dayan, Mehmet Murat Naki \\ Bağcılar Eğitim ve Araştırma Hastanesi, Kadın Hastalıkları ve Doğum Kliniği, İstanbul, Türkiye
}

\section{Özet}

\begin{abstract}
Amaç: Günümüzde benign uterin patolojiler için abdominal histerektomi $(\mathrm{AH})$, vajinal histerektomiden $(\mathrm{VH})$ fazla yapılmaktadır. Total laparoskopik histerektomi (TLH) ise her iki yönteme nazaran daha kısa iyileşme süresi ve günlük hayata dönüşün hızlı olması nedeniyle daha yaygın yapılmaya başlanmıştır. Biz bu çalışmada kliniğimizde yapılan $A H, V H$ ve TLH'ların sonuçlarını karşılaştırdık.
\end{abstract}

Yöntem: Bu çalışmada Bağcılar EAH Kadın Doğum Kliniği'nde 2010 Aralık-2011 Aralık tarihleri arasında benign nedenlerle histerektomi yapılan olgular geriye dönük olarak karşılaştıııldı. Bu sürede $139 \mathrm{AH}$ (\%56.8), 61 VH (\%24.9), 45 TLH (\%18.3) yapılmıştı. Olguların yaşları, pariteleri, hastanede kalış süreleri, komplikasyonları, hematokrit değişiklikleri ve operasyon süreleri kaydedildi. İstatistik analizleri yapıldı.

Bulgular: $\mathrm{AH}, \mathrm{VH}, \mathrm{TLH}$ larda ortalama yaş sırasıyla 49.5, 59 ve 51,6 idi. Parite ortalaması sırasıyla 3, 4.5 ve 4.3'tü. Hastanede ortalama kalış süreleri 3.8 , 3.8 ve 2.9 gün olarak bulundu. TLH olgularının operasyon süresi (139.27 \pm 36.48 dakika); $\mathrm{AH}$ (66.91 \pm 11.64 dakika) ve $\mathrm{VH}(47.50 \pm 9.68$ dakika) grubundaki olguların operasyon süresinden anlamlı olarak uzun bulundu $(p<0.01)$. Olguların hematokrit değişiklikleri benzer saptandı. TLH'larda komplikasyon oranı biraz daha yüksek bulundu.

Sonuç: ABD'de halen histerektomilerin \%70'e yakını abdominal olarak yapılmaktadır. ACOG tarafından birinci sırada $\mathrm{VH}$, ikinci sırada TLH, son olarak AH'lerin tercih edilmesi önerilmiştir. Kliniğimiz yeni bir klinik olmasına rağmen $\mathrm{VH}$ ve TLH'ların toplamı AH'lere yakın olarak bulunmuştur. (Haseki Tıp Bülteni 2013; 51: 112-5)

Anahtar Kelimeler: Histerektomi, endikasyonlar, post-operatif değişiklikler

\begin{abstract}
Aim: Lately, vaginal hysterectomies $(\mathrm{VH})$ are being performed more frequently than abdominal hysterectomies $(\mathrm{AH})$ for benign pathologies. Even then, total laparoscopic hysterectomy (TLH) has been widely done because of its shorter recovery time. In this study, we compared the results of $\mathrm{AH}, \mathrm{VH}$ and TLH performed in our clinic.

Methods: In this study, we retrospectively evaluated the hysterectomies performed between December 2010 and December 2011 for benign uterine pathologies in the Obstetric and Gynecology Clinic at Bağcılar Training and Research Hospital. It is a retrospective study. During this time, $139 \mathrm{AH}$ (56.8\%), 61 $\mathrm{VH}(24.9 \%)$, and $45 \mathrm{TLH}$ (18.3\%) were done. Data including age, parity, length of hospital stay, change in hematocrit, and length of the operations were recorded. Statistical analysis was performed.

Results: The average age of patients who underwent $\mathrm{AH}, \mathrm{VH}$ and TLH was 49.5.0, 59 and 51.6, respectively. The average parity was 3.0, 4.5 and 4.3, respectively. The average length of hospital stay was $3.8,3.8$, and 2.9 days, respectively. Duration of operation (139.27+/-36.48 min) in TLH group was longer than in $A H$ $(66.91+/-11.64 \mathrm{~min})$ and VH groups $(47.50+/-9.6 \mathrm{~min})(p<0.01)$. Changes in hematocrit were similar in the groups. Complications related to TLH seem to be a little more than other procedures.
\end{abstract}

Conclusion: Nearly $70 \%$ of all hysterectomies in USA are made abdominally. The American College of Obstetricians and Gynecologists (ACOG) recommended VH as approach of choice for being associated with better outcomes and fewer complications than either laparoscopic or abdominal approach. Although our clinic is new, the total number of $\mathrm{VH}$ and TLH are similar to that of AH. (The Medical Bulletin of Haseki 2013; 51: 112-5)

Key Words: Hysterectomy, indications, post-operative changes
Yazışma Adresi/Address for Correspondence: Hikmet Koçer Bağcılar Eğitim ve Araştırma Hastanesi, Kadın Hastalıkları ve Doğum Kliniği, İstanbul, Türkiye E-posta: hikmetkocer84@hotmail.com

Geliş Tarihi/Received: 12 Şubat 2013 Kabul Tarihi/Accepted: 17 Kasım 2012
Haseki Tıp Bülteni, Galenos Yayınevi tarafından basılmıştır. The Medical Bulletin of Haseki Training and Research Hospital, published by Galenos Publishing.

TJOD 2012 kongresinde poster olarak sunulmuştur. 


\section{Giriş}

Günümüzde benign uterin patolojiler için minimal invazif tekniklerin yaygınlaşmasına rağmen; abdominal histerektomi $(\mathrm{AH})$ en yaygın kullanılan jinekolojik prosedürdür. $A B D^{\prime}$ de sezaryenden sonra ikinci en sık uygulanan majör cerrahi operasyondur (1-8). Histerektomi için en önde gelen endikasyon uterus leiyomiyomalarıdır (9). ABD'de histerektomi olan kadınların yaş ortalaması 42.7 civarında olup 1980'lerden beri benzer seyrettiği görülmüştür (10).

Geçtiğimiz 10-20 yılda abdominal histerektomiler vaginal histerektomilere $(\mathrm{VH})$ göre üç kat daha fazla tercih edilirdi (2).

Vaginal histerektomiler abdominal histerektomilerle karşılaştırıldığında vaginal histerektomilerde daha az komplikasyon, daha az kan kaybı, daha kısa iyileşme süresi, daha az kan transfüzyonu intiyacı görülmektedir (3). Ancak ciddi cerrahi komplikasyonlar abdominal histerektomiler için \%1.8, vaginal histerektomiler için $\% 5,1$ olarak bulunmuştur (4).

Geçtiğimiz 10-20 yılda histerektomilerin \%70-80'i laparotomi ile yapııırdı (2).

Günümüzde laparoskopik histerektomi daha az morbidite ve daha kısa iyileşme süresine sahip olduğu için daha yaygın yapılmaktadır (5).

Laparoskopik histerektomide abdominal histerektomi ile karşılaştıııldığında daha az post-op ağrı, daha az kan kaybı, günlük aktiviteye daha kolay dönüş görülmektedir (6-7).

Vaginal histerektomi pelvik relaksasyonun az olduğu hastalarda, nulliparlarda, geçirilmiş pelvik cerrahisi olan hastalarda daha az tercih edilir.

Biz bu çalışmada kliniğimizde yapılan abdominal histerektomi $(\mathrm{AH})$, vaginal histerektomi $(\mathrm{VH})$ ve total laparoskopik histerektomilerin (TLH) perioperatif sonuçlarını karşılaştırdık.

\section{Gereç ve Yöntem}

Bu çalışmada Bağcılar Eğitim ve Araştırma Hastanesi Kadın Doğum Kliniği'nde 2010 Aralık-2011 Aralık tarihleri arasında benign nedenlerle histerektomi yapılan olgular geriye dönük olarak karşılaştırıldı.

Aralık 2010-Aralık 2011 tarihleri arasında kliniğimizde $139 \mathrm{AH}$ (\%56.8), $61 \mathrm{VH}(\% 24.9), 45 \mathrm{TLH}$ (\%18.3) yapılmıs. Olguların yaşları, pariteleri, histerektomi endikasyonları, hastanede kalış süreleri, post-op oluşan komplikasyonlar, kan transfüzyonu yapılıp yapılmadığı, hematokritteki değişiklikler, uterus ağırlıkları, operasyon süreleri kaydedildi. İstatistik testleri olarak Kruskal-Wallis testi ve farklılığa neden olan grubun tespitinde Mann-Whitney $U$ testi ve Bonferroni düzeltmesi kullanıldı. Sonuçlar \%95 güven aralığında, $p<0.05$ anlamlılık düzeyinde ve $p<0.01$ ileri anlamlılık düzeyinde değerlendirildi.

\section{Bulgular}

Üç grup arasında istatistiksel incelemeler yapıldı. $\mathrm{AH}$, VH ve TLH'larda ortalama yaş sırasıyla $49.5,59$ ve 51.6 idi. Parite ortalaması sırasıyla $3,4.5$ ve 4.3 idi. Hastanede ortalama kalış süreleri sırasıyla 3.8, 3.8 ve 2.9 gündü. TLH grubunda hastanede kalıs süresi $\mathrm{AH}$ ve $\mathrm{VH}$ gruplarına göre anlamlı olarak daha kısaydı $(p<0.05)$. AH ve $\mathrm{VH}$ grupları arasında fark yoktu.

Laparoskopik histerektomi grubundaki olguların uterus ağırlığı (196.40 $\pm 102.45 \mathrm{~g})$; abdominal histerektomi $(143.64 \pm 38.29 \mathrm{~g})$ ve vaginal histerektomi $(149.07 \pm 35.12$ g) grubundaki olguların uterus ağılığından anlamlı olarak yüksek bulundu $(p<0.01)$. Abdominal histerektomi ile vaginal histerektomi grubundaki olguların uterus ağırlığı arasındaki fark istatistiksel olarak anlamlı değildi ( $p>0.05$ ).

Laparoskopik histerektomi grubundaki olguların operasyon süresi $(139.27 \pm 36.48 \mathrm{dk})$; abdominal histerektomi (66.91 $\pm 11.64 \mathrm{dk}$ ) ve vaginal histerektomi $(47.50 \pm 9.68 \mathrm{dk})$ grubundaki olguların operasyon süresinden anlamlı olarak yüksek bulundu $(p<0.01)$. Abdominal histerektomi grubundaki olguların operasyon süresi $(66.91 \pm 11.64)$ ise vaginal histerektomi $(47.50 \pm 9.68)$ grubundaki olguların operasyon süresinden anlamlı olarak yüksek bulundu $(p<0.01)$.

Her 3 grup hematokritteki değişiklik açısından karşılaştıııldığında anlamlı fark olmadığı görüldü.

Kırk beş TLH olgusunun altısında (\%13.3) komplikasyon izlendi (dört olguda üreter kesisi, bir olguda ana trokar giriş yeri enfeksiyonu ve bir olguda vajinal kaftan barsak sarkması), AH grubunda 139 olgudan altısında (\%4.3) komplikasyon izlendi (beş olguda yara yeri enfeksiyonu, bir olguda üreter kesisi), VH grubunda ise 61 olgudan ikisinde (\%3.27) komplikasyon izlendi (iki olguda da kaf hematomu). TLH grubunda komplikasyon oranı anlamlı olarak yüksek bulundu. $\mathrm{AH}$ ve $\mathrm{VH}$ grupları arasında anlamlı fark yoktu.

\section{Tartışma}

ABD'de halen histerektomilerin \%70'e yakını abdominal olarak yapılmaktadır. 2005 'de ABD'de yapılan 500.000 histerektominin \%64'ü abdominal, \%22'si vaginal ve \%14'ü laparoskopik olarak gerçekleştirilmiştir (11). ACOG tarafından birinci sırada $\mathrm{VH}$, ikinci sırada TLH, son olarak AH'lerin tercih edilmesi önerilmiştir. Benzer şekilde 2009'da Cochrane veri tabanında 34 çalışmanın değerlendirildiği bir meta-analizde eğer mümkünse VH'nin ilk sırada tercih edilmesi gerektiği, VH mümkün değilse ikinci sırada TLH'ın tercih edilmesi gerektiği sonucuna ulaşılmıştır (12). Kliniğimizde 1 yıllık süre içinde $139 \mathrm{AH}(\% 56.8), 61 \mathrm{VH}$ (\%24.9), 45 TLH (\%18.3) yapılmıştır. Kliniğimiz yeni bir klinik olmasına rağmen $\mathrm{VH}$ ve TLH'ların toplamı AH'lere yakın olarak bulunmuştur. VH ve TLH olarak başlanan 
hiçbir olguda; $A H^{\prime}$ ye dönülmek zorunda kalınmamıştır. Öğrenme eğrisine bağlı olarak bizim çalışmamızda TLH'ların ortalama operasyon süresi ve komplikasyon oranları $\mathrm{AH}$ ve $\mathrm{VH}^{\prime}$ ye göre anlamlı olarak yüksek bulunmuştur. Öğrenme süreci arttıkça hem operasyon süresinin hem de komplikasyonların azaldığı cerrahide iyi bilinen bir gerçektir. Laparoskopik histerektomi göreceli olarak yeni bir tekniktir ve deneyim arttıkça cerrahi sonuçlarda anlamlı iyileşmeler sağlanmaktadır.

2006-2010 yılları arasında Tayland'da yapılan geriye dönük karşılaştırmalı bir çalışmada TLH grubunda 30 olgu ve $\mathrm{AH}$ grubunda 30 olgu incelenmiştir. TLH grubunda

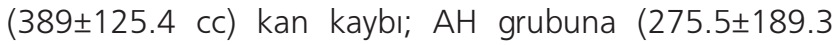
cc) göre daha fazla bulunmuştur. Operasyon süresi TLH

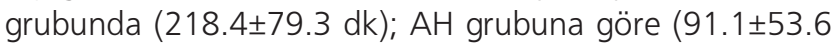
dk) anlamlı olarak uzun bulunmuştur. Hastanede kalış

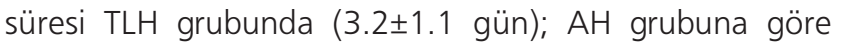
(5.3 \pm 4.3 gün) anlamlı olarak kısa bulunmuştur. Postoperatif komplikasyon oranları TLH grubunda (\%46.6), AH grubuna göre (\%43.3) fazla olmasına rağmen anlamlı fark bulunamamıştır. Sonuç olarak Tayland'da yapılan bu çalışmada TLH grubunda kan kaybı daha fazla, operasyon süresi daha uzun olmasına rağmen TLH etkili, güvenilir ve yaşam kalitesini arttırıc bulunmuştur (13). Ancak Walsh ve arkadaşlarının TLH ile AH olgularını karşılaştırdıkları bir meta-analizde; peri-operatif komplikasyon oranları (OR 0.19; 95\% Cl 0.07-0.50) ve kan kaybı miktarı (183 ml'ye karşın $346 \mathrm{ml}$ ) TLH grubunda daha düşük bulunmuştur. Benzer olarak bu çalışmada da TLH grubunda hastanede kalış süresi daha kısa bulunmuştur (14).

Warren ve arkadaşlarının yaptığı geriye dönük bir çalışmada minimal invazif prosedür (TLH ve $V H$ ) ve $A H$ uygulanan 15.404 olgu incelenmiştir. Olguların \%23'üne TLH, \%20'sine VH ve \%57'sine AH uygulanmıştır. Postoperatif enfeksiyon oranları AH grubunda \%18, TLH grubunda \%15, VH grubunda \%14 olarak bulunmuştur. Hastanede kalış süresi $\mathrm{AH}$ grubunda ortalama 3.7 gün, TLH grubunda 1.6 gün ve VH grubunda 2.2 gün olarak bulunmuştur. Bu çalışmada klinik ve ekonomik sonuçlar minimal invazif yöntemlerin kullanımasını destekler niteliktedir (15).

Başka bir çalışmada Vaisbuch ve arkadaşları geriye dönük olarak 167 TLH ve 119 AH olgusunu karşılaştırmışlardır. İki grup arasında yaş, vücut kitle indeksi (VKi), önceki abdominal cerrahi öyküsü, uterus ağırlığı, majör ve minör komplikasyon oranları benzer bulunmuştur. Ancak bizim çalışmamızda 45 TLH olgusunun altısında (\%13.3) komplikasyon izlendi (dört olguda üreter kesisi, bir olguda ana trokar giriş yeri enfeksiyonu ve bir olguda vajinal kaftan barsak sarkması), AH grubunda 139 olgudan altısında (\%4.3) komplikasyon izlendi (beş olguda yara yeri enfeksiyonu, bir olguda üreter kesisi), $\mathrm{VH}$ grubunda ise 61

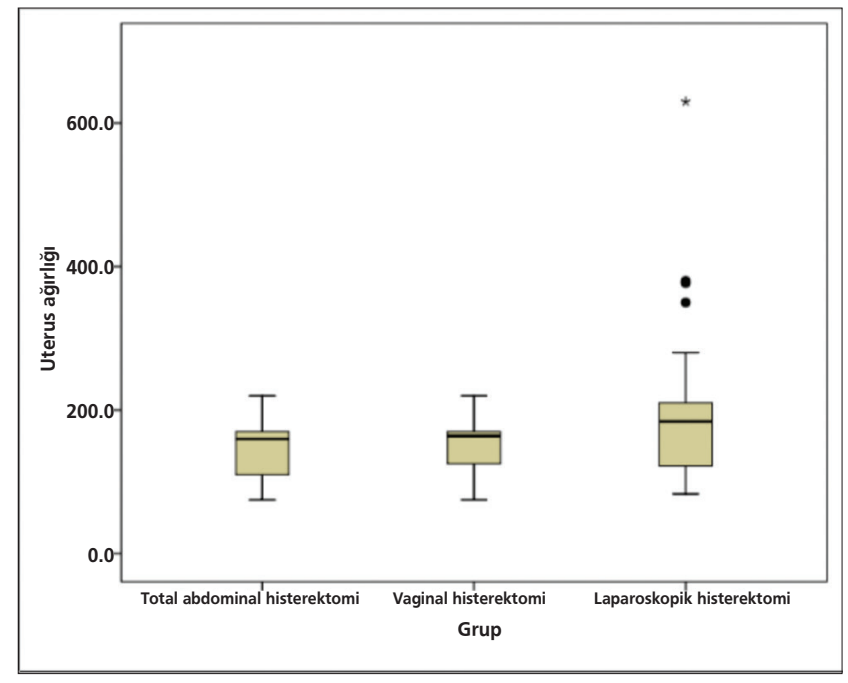

Şekil 1. Uterus ağırlığı

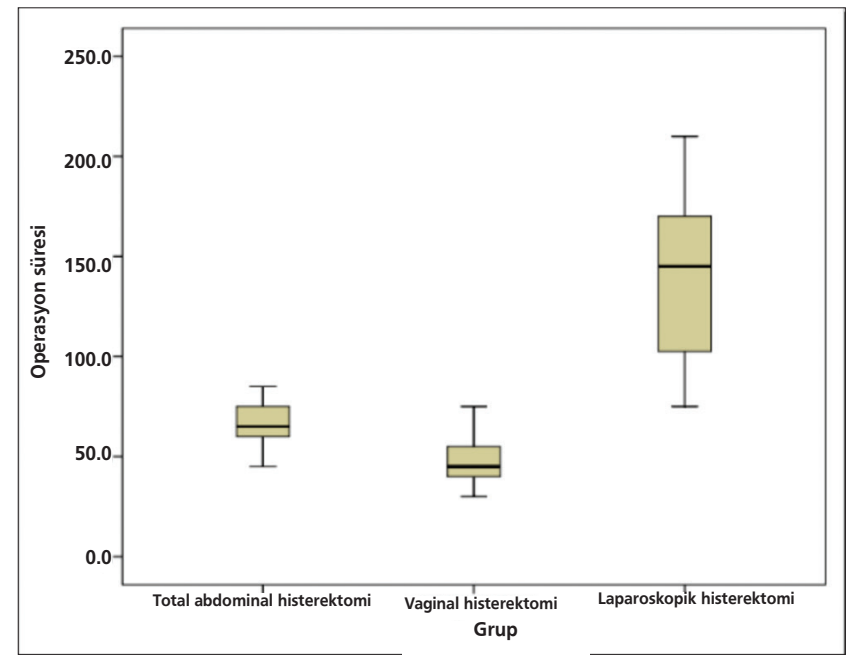

Şekil 2. Operasyon süresi

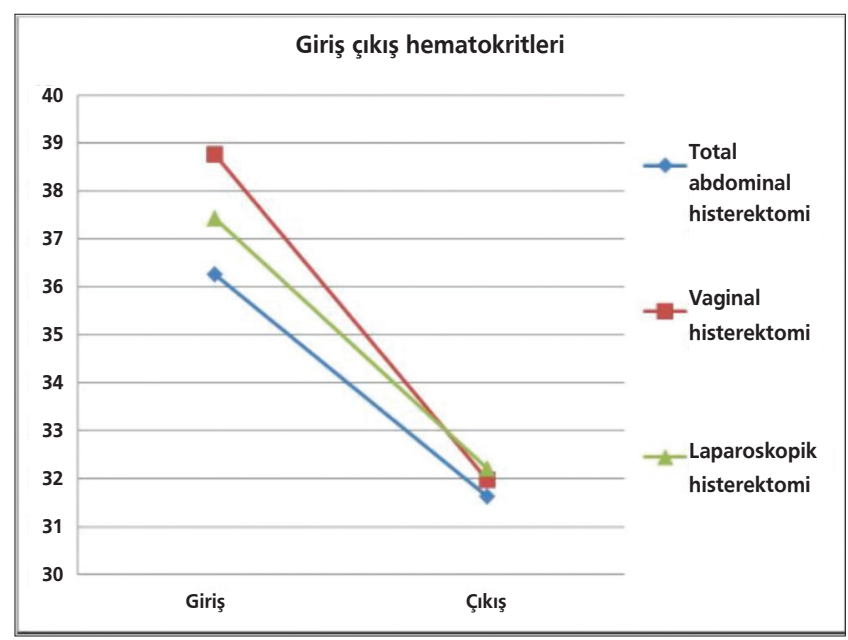

Şekil 3. Hematokrit oranı 
olgudan ikisinde (\%3.27) komplikasyon izlendi (iki olguda da kaf hematomu). TLH grubunda komplikasyon oranı $\mathrm{AH}$ ve $\mathrm{VH}$ gruplarına göre anlamlı olarak yüksek bulundu. $\mathrm{AH}$ ve $\mathrm{VH}$ grupları arasında fark yoktu. Yine Vaisbuch ve arkadaşlarının çalışmasında operasyon süresi TLH grubunda (156 $\pm 40 \mathrm{dk}), \mathrm{AH}$ grubuna göre (91 $\pm 33 \mathrm{dk})$ anlamlı olarak uzun bulunmuştur $(p<0.01)$. Bizim çalışmamızda da laparoskopik histerektomi grubundaki olguların operasyon süresi $(139.27 \pm 36.48 \mathrm{dk})$; abdominal histerektomi $(66.91 \pm 11.64 \mathrm{dk})$ ve vaginal histerektomi $(47.50 \pm 9.68$ dk) grubundaki olguların operasyon süresinden anlamlı olarak yüksek bulundu $(p<0.01)$. Abdominal histerektomi grubundaki olguların operasyon süresi $(66.91 \pm 11.64)$ ise vaginal histerektomi $(47.50 \pm 9.68)$ grubundaki olguların operasyon süresinden anlamlı olarak yüksek bulundu $(p<0.01)$. Vaisbuch ve arkadaşlarının çalışmasında hastanede ortalama kalış süresi TLH grubunda (3.9 gün), AH grubuna göre (6.55 gün) daha kısa bulunmuştur. Sonuç olarak bu çalışmada laparoskopi öğrenme eğrisi sırasında bile güvenilir ve düşük komplikasyonlu olarak sunulmuştur (16). Bizim çalışmamızda hastanede ortalama kalış süreleri $\mathrm{AH}$ grubunda 3.8 gün, $\mathrm{VH}$ grubunda 3.8 gün ve $\mathrm{TLH}$ grubunda 2.9 gündü. TLH grubunda hastanede kalış süresi $\mathrm{AH}$ ve $\mathrm{VH}$ gruplarına göre anlamlı olarak daha kısaydı. $\mathrm{AH}$ ve $\mathrm{VH}$ grupları arasında fark yoktu.

Ayrıca Vaisbuch ve arkadaşlarının yaptığı çalışmada TLH ve AH grupları arasında post-operatif birinci gündeki hematokrit değerlerindeki düşüş benzerdi. Bizim çalışmamızda da üç grup arasındaki post-operatif birinci gün hematokrit değerlerindeki düşüşler benzer olarak bulundu.

Finlandiya'da yapılan bir çalışmada $\mathrm{AH}^{\prime}$ de ortalama uterus ağırlı̆ı 290.4 g, VH'de 108.7 g ve laparoskopik yöntemde $195 \mathrm{~g}$ olarak bulunmuştur. Bu sonuçlarla vajinal ve laparoskopik yöntemlerde uterus ağırlıkları istatistiksel olarak abdominale göre anlamlı derecede hafif kalmaktadır (17). Bizim çalışmamızda ilginç olarak laparoskopik histerektomi grubundaki olguların ortalama uterus ağırlığı (196.40 $\pm 102.45 \mathrm{~g}$ ); abdominal histerektomi $(143.64 \pm 38.29 \mathrm{~g})$ ve vaginal histerektomi $(149.07 \pm 35.12$ g) grubundaki olguların uterus ağırlığından anlamlı olarak yüksek bulundu $(p<0.01)$. Abdominal histerektomi ile vaginal histerektomi grubundaki olguların uterus ağırlığı arasındaki fark istatistiksel olarak anlamlı değildi ( $p>0.05)$.

Günümüzde hastanede daha az kalış süresi, daha az kan kaybı olması nedeniyle histerektomi yöntemlerinden daha az invazif olanlar yaygınlaşmaya başlamıştır. Tüm bu çalışmalara baktığımızda histerektomi şekline, hasta ile detaylı konuşularak, cerrahi prosedürün hastaya faydası ve zararları değerlendirilerek karar verilmelidir.

\section{Kaynaklar}

1. Farquhar CM, Steiner CA. Hysterectomy rates in the United States 1990-1997. Obstet Gynecol 2002;99:229-34.

2. Wilcox LS, Koonin LM, Pokras R, Strauss LT, Xia Z, Peterson HB. Hysterectomy in the United States, 1988-1990. Obstet Gynecol 1994;83:549-55.

3. Ribeiro SC, Ribeiro RM, Santos NC, Pinotti JA. A randomized study of total abdominal, vaginal and laparoscopic hysterectomy. Int J Gynaecol Obstet 2003;83:37-43.

4. Dicker RC, Greenspan JR, Strauss LT, et al. Complications of abdominal and vaginal hysterectomy among women of reproductive age in the United States. The Collaborative Review of Sterilization. Am J Obstet Gynecol 1982;144:841-8.

5. Reich H, DeCaprio J, McGlynn NF. Laparoscopic hysterectomy. J Gynecol Surg 1989;5:213-6.

6. Liu CY. Laparoscopic hysterectomy. Report of 215 cases. Gynecol Endosc 1992;1:73-7.

7. Reich $H$, Ribeiro SC, Vidali A. Hysterectomy as treatment for dysfunctional uterine bleeding. Baillieres Best Pract Res Clin Obstet Gynaecol 1999;13:251-69.

8. Benrubi Gl. History of hysterectomy. J Fla Med Assoc 1988;75:533-8.

9. Gambone JC, Reiter RC. Nonsurgical management of chronic pelvic pain: a multidisciplinary approach. Clin Obstet Gynecol 1990;33:205-11.

10. Kjerulff KH, Guzinski GM, Langenberg PW, Stolley PD, Moye NE, Kazandjian VA. Hysterectomy and race. Obstet Gynecol 1993;82:757-64.

11. Wu JM, Wechter ME, Geller EJ, Nguyen TV, Visco AG. Hysterectomy rates in the United States, 2003. Obstet Gynecol 2007;110:1091-5.

12. Nieboer TE, Johnson $N$, Lethaby $A$, et al. Surgical approach to hysterectomy for benign gynaecological disease. 2009;3:CD003677.

13. Sutasanasuang $\mathrm{S}$. Laparoscopic hysterectomy versus total abdominal hysterectomy: a retrospective comparative study. J Med Assoc Thai 2011;94:8-16.

14. Walsh CA, Walsh SR, Tang TY, Slack M. Total abdominal hysterectomy versus total laparoscopic hysterectomy for benign disease: a meta-analysis. Eur J Obstet Gynecol Reprod Biol 2009;144:3-7.

15. Warren L, Ladapo JA, Borah BJ, Gunnarsson CL. Open abdominal versus laparoscopic and vaginal hysterectomy: analysis of a large United States payer measuring quality and cost of care. J Minim Invasive Gynecol 2009;16:581-8.

16. Vaisbuch E, Goldchmit C, Ofer D, Agmon A, Hagay Z. Laparoscopic hysterectomy versus total abdominal hysterectomy: a comparative study. Eur J Obstet Gynecol Reprod Biol 2006;126:234-8.

17. Wattiez A, Soriano D, Cohen SB, et al. The learning curve of total laparoscopic hysterectomy: comparative analysis of 1647 cases. J Am Assoc Gynecol Laparosc 2002;9:339-45. 